\title{
Analysis on the Supply Chain Optimization of Northeast Agricultural Products under the Background of "Internet+"
}

\author{
Dahai Wang ${ }^{1, a}$ \\ ${ }^{1}$ College of Humanities and Sciences of Northeast Normal University, Changchun, \\ Jilin Province 130117, China \\ a11268222@qq.com
}

Keywords: Internet+; Northeast agricultural products; Supply chain optimization; Countermeasures

Abstract. With the accelerated construction of agricultural modernization in Northeast China, agricultural products from production to sales have formed a set of supply chain system, but it cannot completely adapt to the development of the Internet + background. Because of the characteristics of northeast agricultural products and other reasons, it is an important way to promote the economic development of northeast area through the Internet + model. This paper first analyzes the connotation of Internet + , studies the characteristics of existing northeast agricultural products supply chain, and analyzes the optimization way for northeast agricultural products supply chain according to the current situation.

Since ancient times, northeast China has been an important agricultural product producing area in our country. Northeast China is not only rich in soil, but also high in automation and mechanization, and has become an important agricultural product supplying place in our country. With the continuous change of agricultural product market in our country, the whole agricultural products market is more concentrated. However, because of geographical problems, the northeast agricultural products are directly exported overseas, and the border trade of agricultural products is relatively concentrated, with a favorable market in the world. [1]

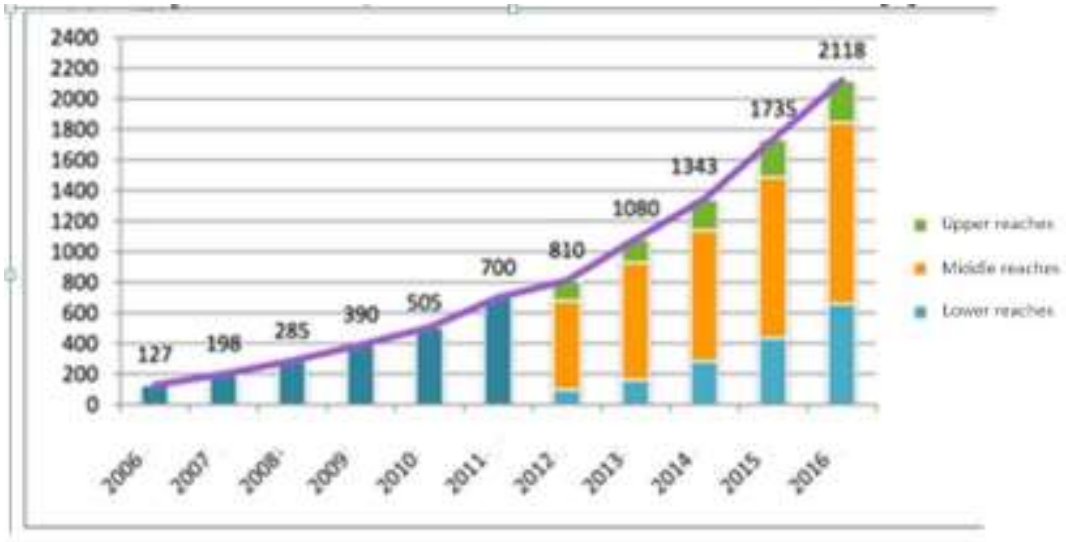

Figure 1-1. Finite Output value of agricultural products in northeast China at the upper, middle and lower reaches

(unit: 100 million)

Due to own reasons, the agricultural products in northeast China are very prone to overstock in the whole economic development, which is easy to cause large losses of agricultural products. Therefore, in this context, the supply chain will be improved and optimized correspondingly, so as to promote the rapid turnover of agricultural products, obtaining certain bullwhip effect on the development of agricultural products in northeast China. [2]Under the condition of supply chain, some leading enterprises should take the lead to form certain market space, and quickly circulate agricultural products to the whole country, and eventually form a logistics network in the whole country, to speed up the development and industrial layout of northeast agricultural products. 


\section{The Connotation of Internet + and the Agricultural Product Supply Chain}

Internet + is proposed as a national policy in our country based on the rapid development of Internet, having obtained multipartite policy support. Internet + at this stage has penetrated into various industries, and driven the economic development form and speed in many industries. [3]This kind of business model is by the rapid development of economy and combines the basic of traditional industries, and ultimately transform the traditional business model through connecting the Internet. The related management and development thinking of Internet + are the important foundation of the transformation and upgrading of traditional industries at this stage. Without support of thinking, there is no further economic development as well as the exploitation and development of Internet mode. In the development of Internet economy, the power of the Internet will be better brought into traditional industries through certain channels of Internet + . The transformation of this channel not only makes the traditional industry have economic development power, but also breaks the regional restrictions of the traditional industry. In addition, the Internet + platform is an important feature of its development. In the development of Internet, through a certain economic development and innovation of related modes, there are many logistics platforms that connect products across the country to a large Internet platform[4].

The Supply Chain is finally transplanted with the development of the value chain. In 1980, the research on supply chain began in the world. The supply chain is a link between the upstream suppliers and the downstream users, realizing mutual interconnection. In the development of agricultural products, the supply chain is mainly based on the planting of agricultural products and the network connection structure system, like storage, circulation and sales. In the application of supply chain in agricultural products, the main difficulties are the suppliers, distributors and the relevant final consumers. At the present stage, the northeast is an internationally important supplier of grain, seeds and feed. The value chain can realize the unified planning and deployment for the logistics, the fund flow as well as the corresponding information flow. [5]

\section{Status quo of the Development of Agricultural Product Supply Chain in Northeast China}

The Development Characteristics of the Existing Agricultural Product Supply Chain in Northeast China. The supply chain development of agricultural product in Northeast China is mainly related to the corresponding suppliers, distributors of related commodities and corresponding consumers. Through analysis, it can be found that the agricultural products which were sold, will eventually return to the consumers. Because the corresponding economic development is not perfect, making related chain in the whole economic development disharmonious, and the supply chain needs to be improved.

The Operation mode of Agricultural Product Supply Chain in Northeast China. The existing models of agricultural product supply chain in northeast China can be divided into 4 types:

Take the scattered farmers as the center

In this transaction mode, because transactions are often located in the fields, leading to small-scale transaction scale and cash flow, which is difficult to shape scale, and corresponding fresh agricultural products in the whole market is in difficult preservation, leading to very small-scale transaction scale and difficult long-distance transportation.

Take the middleman as the center

In this model, because the corresponding middleman is an important transit power, directly making the middleman an important channel connecting the field and wholesalers in the entire trade of agricultural product. However, because middlemen practically need to earn profit, a large number of forcing down prices exist in the economic development and agricultural product trade, directly leading to farmers' interest loss. In this mode, the corresponding middlemen serve as the important backbone. [6]In practical transaction and circulation of agricultural product, due to step-by-step distribution and circulation and the consumption of agricultural products themselves, all these directly lead to much higher prices of agricultural products when reaching the consumer's table, making agricultural products lack of competitiveness in the market. 
Take the leading enterprise as the center

In this mode, the whole agricultural product is under the operation of the leading enterprises, and farmers serve as coordination force while planting. Later, the leading enterprises purchase, package and arrange, and then sell and circulate[7].

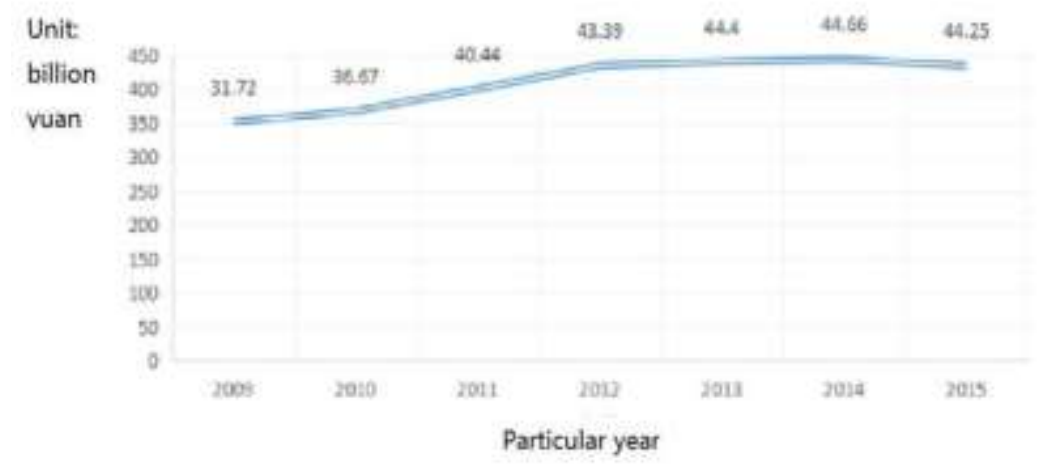

Figure 2-1 Finite The management and development of the leading enterprises in northeast China

In this mode, the cooperation can last for a long time because of its own advantages, like the brand strength of leading enterprises as the support, relatively high and guaranteed quality of agricultural product. This is also conducive to the circulation of the market, and is more trusted by consumers in production and operation. Because of the support from leading enterprises, farmers' income and sales are relatively stable.

Take farmers' cooperatives as the center

In this model, producers of agricultural products carry out handover in a spontaneous or organized way, which eventually form a good cooperation mode. Under this cooperation mode, because the organization of farmers is relatively large and the production is relatively stable, making the whole agricultural production and sales quantity relatively very large, it is extremely easy to form a good bargaining power.

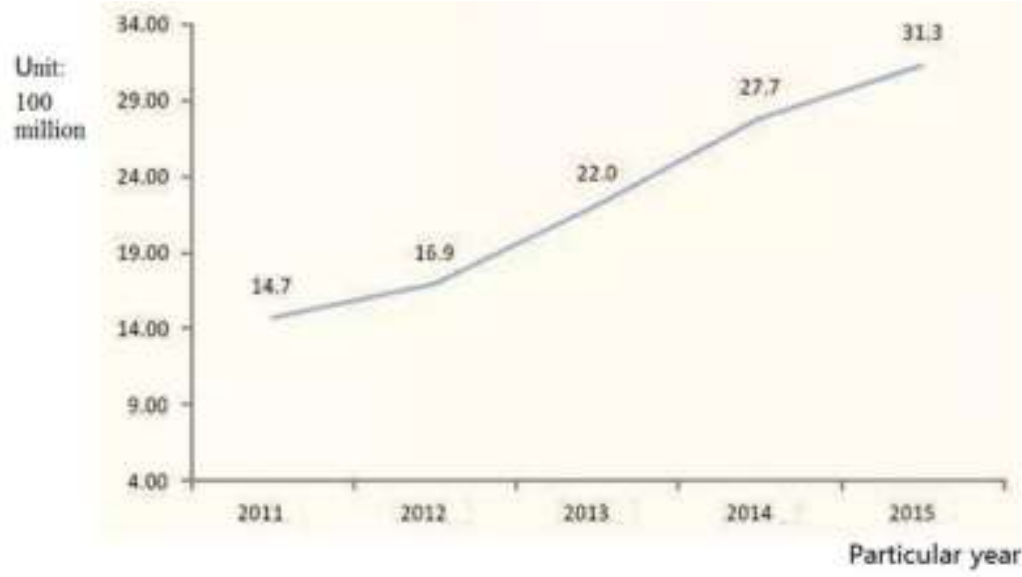

Figure 2-2. Finite Agricultural production management of agricultural cooperatives in Northeast China

In the market circulation, it is also a favorable organization mode, and due to the constraints of organization internal, the quality of agricultural products is relatively high, obtaining strong speaking right in the market. Furthermore, it has the ability to cooperate with large enterprises, so it has a certain market space. 


\section{Existing problems in the supply chain of agricultural product in northeast China}

In the economic development of northeast China, it needs good economic development as support. Under reasonable economic development, although the farmers are producers of agricultural products, they are not the organizers and operators of the agricultural product supply chain, which leads to the corresponding imbalance of economic development and uneven benefit distribution. The main problems are as follows:

Backward Level of Production Information in Agricultural Product. The northeast China has a relatively low information level. At this stage, although there are leading of large farms, production organization and cooperatives, with a relatively high mechanization level, many areas still carry on self-production and sales, which is not only relatively low in the mechanization level, but also blocked by corresponding information level, directly leading to the waste of land. Furthermore, the quality of corresponding agricultural products is low, which seriously wastes land resources. As the whole market economic resources is relatively weak, low level of the market, a lot of agricultural products lie in the production stage of raw materials and sales stage, with relatively low added value, lack of deep processing, which directly results in relatively weak market competitiveness, and the actual value of agricultural product circulation is relatively small.

Backward Logistics Technology for Agricultural Products. At this stage, because of own limitations for the northeast agricultural products, the production of agricultural products and the sales level is relatively low. In addition, the lag of logistics technology directly the lead to the agricultural products cannot account for great advantage in logistics. Due to the limitation of logistics technology, a lot of vegetables and fruit cold need chain transportation. However, the limitation of technology results in relatively low intelligent transportation level of agricultural products, which is difficult to adapt to the fierce competition in the market, and there exist more serious losses of many agricultural products in logistics [5]. Moreover, because of the restriction of the whole market development, the cold chain logistics transportation in the northeast China is relatively weak, which directly leads to restricted development of corresponding market, and the cold chain transportation is difficult to meet the market demand, which needs urgent improvement.

Lack of Information Service Platform for Agricultural Products. Because the development of the information service platform is limited, the development of agricultural products in northeast China confronts many limitations, and the market conditions are relatively poor. Due to poor information platform, it directly makes farmers difficult to get good profits in production, and it is very easy to cause dull sale of farmers' agricultural products, resulting in great losses. Because of insufficient understanding of the market and information asymmetry, a lot of farmers suffer frequent economic losses in the development of the market economy. Moreover, the information asymmetry between dealers and farmers also directly lead to the dealer cannot find the corresponding farmers, resulting in dull sale of corresponding agricultural products.

But in the economic development of northeast China, the supply chain has a low efficiency and a certain low management level. Among them, the relatively serious problem in the supply chain management is that the quality cannot be guaranteed, seriously hindering the economic development in related areas[8].

\section{Strategy of Optimizing the Agricultural Product Supply Chain Under the Background of "Internet +"}

Economic Development Under the Background of O2O. Under the background of Internet + , the development of the supply chain must take the e-commerce as the leading system. In the background of the supply chain, the corresponding circulation velocity and the rational integration of related logistics can be enhanced. Based on the e-commerce background, the supply chain model mainly strengthens the logistics distribution and promotes the corresponding logistics distribution model. The promotion of this model is mainly based on the mobilization of the downstream consumers, which has a very high acceleration effect in the economic development. $\mathrm{O} 2 \mathrm{O}$ model is a 
good supply network system based on the combination of suppliers and consumers, and has a relatively large development prospect.

Form a Strategic Alliance Through the Processing Alliance, and this Model can Promote the Development and Cooperation of Enterprises in Corresponding Economic Development. Through this alliance way, it can ultimately enhance the supply chain integration in corresponding economic development mode, and greatly reduce the consumption of resources. Product distribution can better reduce the economic cost between corresponding suppliers and consumers. This model can better promote corresponding economic development model conditions, and integrate resources to maximize the benefits. On the basis of the industrial alliance, it can improve the level of information communication in related economic development level, and realize the scientific configuration of the economic development[9].

Introduction of Intelligent Logistics Model. The ways to improve the intelligent logistics model are as follows:

The development of intelligent logistics system needs support from many parties. The intelligent logistics mode can not only enhance the processing of corresponding information and the ability of receiving information, but also improve the logistics mode innovation in corresponding economic development.

Improve the development level of the industry through the development of core enterprises.

By improving the optimized distribution of corresponding logistics channels, the whole information network is optimized and corresponding economic development conditions are finally integrated.

The development level of logistics enterprises can also enhance corresponding logistics development mode, so as to better innovate and enhance the corresponding modes in the whole economic development.

Encourage the Development of Rural E-commerce. In the development of the rural economy, it needs to constantly improve corresponding economic development level, and combines certain rural basic industries to carry out optimal configuration of industries. For example, combine the e-commerce with rural production, and bring e-commerce into village service, realizing direct delivery of agricultural products from the field to the consumers.

Promote the Establishment of Big Data Platform for Agricultural Products in Northeast China with the Leadership of the Government. In 2014, due to the whole market economic development, big data was written into the report of economic development. In addition, the construction of big data and other platforms has become an important strategic resource at this stage. [10]Big data needs analysis of massive data sets. The development of big data information system can provide good information exchanges for the economic development of northeast area. Moreover, due to the rising of market economy, the application of big data in northeast China can be better applied, which not only can coordinate the government's control, but also can coordinate the market circulation and transport.

The application of big data can directly improve 4 functions of logistics in northeast China.

Through the construction of provincial information platform, it can not only achieve good logistics transportation in the whole country, but also achieve information sharing, eventually forming certain strength of market economy development, and finally forming information sharing and rational allocation of resources.

Through the continuous improvement of the information system, it can not only realize the corresponding information communication, but realize the strengthening of certain logistics supervision.

From the development of information system, the information of traditional logistics and the flow of goods need to be extracted. In the extracted information, a lot of information summary can better provide good support for the intelligent logistics to, so as to change the corresponding service quality change, that is to change from providing information to providing decision services; 
In the development of logistics, good integration can be obtained, and certain opportunities and development can be provided for corresponding logistics development, which can not only better build a good platform, but also provide some data support.

When introducing Internet + idea into cold chain logistics system, it can not only provide good opportunities for the development and construction, but can provide a good foundation for the healthy development and supervision of corresponding agricultural products.

In summary, under the background of Internet + , through the integration of industrial chain, ultimately enhance corresponding economic development mode, and ultimately form good information integration, so as to achieve the maximum benefits of agricultural products.

\section{Acknowledgements}

The Education Department of Jilin Province, "13th Five-Year" social science research project " 'Internet + ' under the environment of northeast agricultural products supply chain system" (Ji UNESCO Zi [2016] No. 504th)

\section{Reference}

[1] Jiang Qian. Analysis on the Supply Chain Optimization of Agricultural Product under the Background of Internet +. [J] Commercial Economy Study, 2016,15:171-173

[2] Lu Changsong. Elementary Analysis on the Supply Chain of Agricultural Products .[J] Logistics Engineering and Management, 2011,33 (5): 60-76

[3] Zhangchi, Research on key technologies of transparent supply chain of agricultural products and their application. [D] Agricultural University of China

[4] Cui yuan. Existing Problems and Countermeasures in the Logistics and Distribution of Fruit and Vegetable Products in Jilin Area. [J] China's agricultural resources and zoning, 2016,37 (7): 220-223

[5]ZhangNanYan. Agricultural interconnection leads the " circulation of internet plus" innovation practice [N]. International Business Daily,2016-10-20

[6] Du Yonghong. Research on the System Construction of Intelligent Supply Chain for Agricultural Products. [J]Economic Review, 2015, (6): 75-78

[7] RanLongNan. Embrace the internet Shenzhen agricultural products to build a green trading system [N].China Business Daily,2016-03-25

[8] Song Yi. Research on the Integration Mode of Supply Chain for Agricultural Products [D] Huazhong Normal University, 2015

[9] Xu Ying. Research on the Choice of Logistics Mode for Distinctive Agricultural Products in Jiangxi under the Internet $+[D]$ East China Jiaotong University 2015.

[10] Wang Baiyi, Sun Qingfeng. Research on the Construction of Logistics Information Platform and Building Countermeasures in the Era of Big Data. [J] Information Science, 2016,34 (3): $52-61$ 